\title{
A COMPILATION AND REVIEW OF EXISTING : SAFETY ANALYSES \\ FOR FUELED SUBASSEMBLIES IN EBR-II
}

by

\author{
J. L. Giliette
}

EBR-II Project

Argonne National Laboratory.

Argonne, Illinois - Idaho Falls, Idaho

December 1971

Work performed under the auspices of the U. S. Atonic Energy Commission

\section{NOTICE.}

This report was prepared an an account of work sponsored ty the United States Government. Neither the United States nor the United States Atomic Energy Commission, nor any of their employees, nor any of their contractors, subcontractors, or their employees, makes any warrauty, express or implied, or assumes any legal liability or responsibility for the accuracy, complcteness or usefulness of any information, apparasus, product or process disclosed, or represents that its use would not infringe privately owned rights. 
TABLE OF CONTENTS

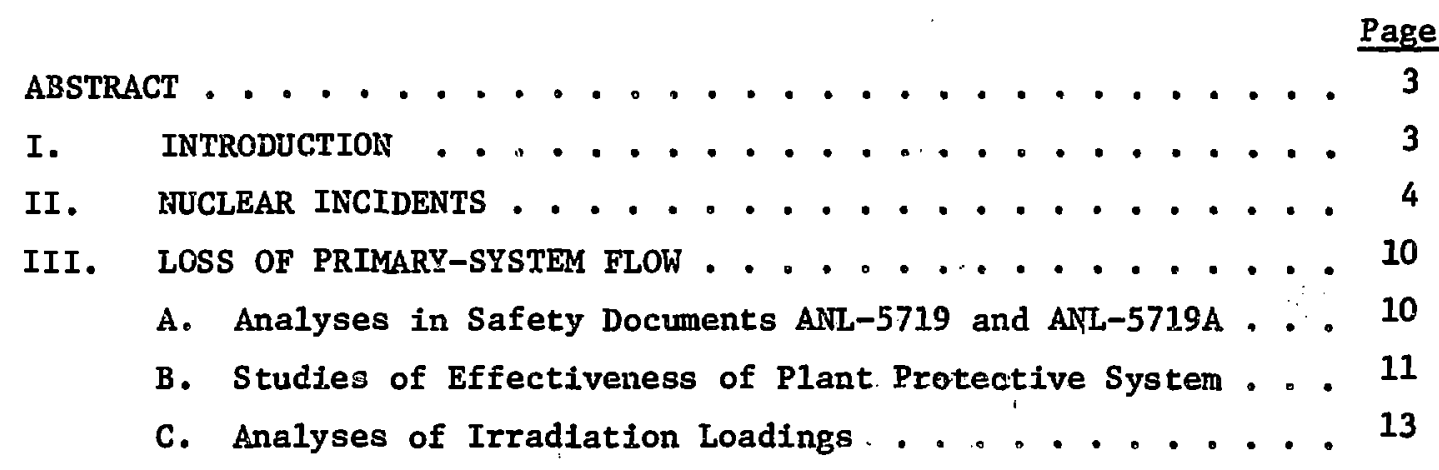

IV. FAILURE OF FUEL-ELEMENT CLADDING ............... 14

A. Analyses of Effects of Flow Blockage in ANL-5719A.. . . 14

B. Later Analyses Related to Failures of Fuel-element cladding ..................... 15

V. OPERATION OF EBR-II WITH SIGNIFICANT OXIDE-FJEL CONTENT . . 19

vi. MISCELlaneous aNaLYSES . . . . . . . . . . . 22

VII. CONClustolis . . . . . . . . . . . . . . . . 23

REFERENCES . . . . . . . . . . . . . . . . . . 24

LIST OF TABLES

No.

Title

Page

I. Consequences of Nuclear Incidents: All-metal-fueled Core . . 6

II. Consequences of Nuclear Incidents at Reduced Flow and for Other Types of Cores . . . . . . . . . . . . . . 8

III. Fuei Temperatures upon Loss of Primary-system Flow urider Most-pessimistic Assumptions: All-metal-fueled Core . . . . 12

IV. Effect of Flow Blockage on Fuel Temperatures, as Analyzed in ANL-5719A . . . . . . . . . . . . . . . 16 
A COMPILATION AND REVIEW OF EXISTING SAFETY ANALYSES

FOR FUELED SUBASSEMBLIES IN EBR-II

by

J. L. Gillette

ABSTRACT

The results of studies dealing with the safety considerations of fueled subassemblies in EBR-II are summarized。 Most of these studies are concerned with the response of oxide-fueled subassemblies to the abnormal incidents postulated and analyzed in the EBR-II safety documents; others deal with the overall behavior of the reactor or with the response of the plant protective system to these incidents. Safety studies on metal-fueled subassemblies are also presented so that a basis for comparison can be established.

\section{INTRODUCTION}

A knowledge of the operational behavior, under steady-state and transient conditions, of subassemblies fueled with mixed oxides is of primary importance to the LMFBR program. As a part of this program, an increasing number of experimental subassemblies fueled with mixed oxides are being irradiated in EBR-II. The analyses in. the original EBR-II. safety documents $^{1,2}$ (referred to hereafter as ANL-5719 and ANL-5719A) were concerned with the operational characteristics of the uranium metal-5..wt \% fissium alloy fuel elements and the depleted-uranium blanket elements. It was necessary, therefore, to analyze the behavior of the mixed-oxide fuel under the same conditions to determ? ne if the operation of the reactor with a significant oxide-fuel invencory is consistent with the intent of the safety documents. The results of these analyses have been compiled and reviewed and are summarized in this report. Although this report will not present all detalls of each analysis, the pertinent conclusions and salient discussion will be described. 
Many of the pertinent safety questions have been addressed in Ref. 3, which is primarily in support of the operation of EBR-II as an irradiation facility at its design power level of $62.5 \mathrm{MWt}$. The report you're reading summarizes a class of pertinent safety-related analyses in a forn suitable for easy cross-comparison of the analyses. Because Ref. 3 discussies many of these analyses in considerable detail, it will be referenced often in this report.

In the following sections, a number. of incidents. are hypothesized, and. the consequences are determined. These. incidents. have been studied in order. to examine the behavior of the fuel and the reactor under the most-severe. imaginable conditions.and.to.determine. the indigenous safety. characteristics of the various fuels.in the reactor. It.should.be recognized that for these incidents to occur would require either or both of the following conditions: gross mismanagement or a complete loss of administrative control; and a . complete malfunctioning of all safety devices in the system.

\section{NUCLEAR INCIDENTS}

The first conditions considered in this report are those.which would exist during and after various uncontrolled reactivity insertions. . Six reactivity-insertion incidents (cases) were.studied (except for Case 4; the reactor was under zero-flow conditions):

1. Insertion of safety rods.at the normal.speed of $2 \mathrm{in.} / \mathrm{min}$ into a delayed critical-reactor at zero-power.*

2. Insertion of the central driver subassembly at the regular speed of $6 \mathrm{in.} / \mathrm{min}$ oyeft the, last $2.4 \mathrm{in}$ of travel into a delayed critical reactor at zero power.

3. Insertion of a single control.rod at 5 in./min into a delayed critical reactor at.zero.power.

4. Same as Case 3 except that the reactor is at.full-power and full flow.

5. Dropping of the sentral driver subassembly into a delayed critical reactor at zero power.

6. Same as Cise.2.except that the subassembly is inserted at $72 \mathrm{in.} / \mathrm{min}$.

*At zero power, the reactor is at the source power level of approximately $8 \mathrm{~W}$. 
Under the assumption.that.the plant.protective system (PPS) falled. to respond, the above incidents were examined.for the original, metalfueled core in Appendix A of ANL-5719. The consequences reported there are summarized in the second colum of.Table $I$. Case 5 represents the most severe incident because fuel melting. would be initiated in less than 0.2 sec. The reactor would be prompt critical at this time, and the subsequent course of the excursion was considered.to be uncertain.

The last column of Table $I$.1sts the approximate times required to reach the reactor period trip setpoint ${ }^{*}$ and the power-level trip setpoint. for each of these incidents. The times to reach the period.trip.point. were taken from a recent study 4 . of the pPS. The times to reach the powerlevel trip point were estimated from the appropriate curves. of power versus time presented in a more up-to-date analysis of these reactivity-insertion incidents. 5 Except for Case 5, the reactor could be scrammed by either the period trip or the power-level.trip before fuel melting or eutectic formation would be initiated. For Case.5, fuei melting would be initiated even though the reactor scrammed almost immediately.

These same reactivity-insertion incidents were studied in Appendix F of ANL-5719A. This document takes into consideration all the differences between the original design. of the reactor (the basis of ANL-5719). and..1ts actual construction. As shown in Table I, under the colum entitled ANL-5719A, the consequences were found to be about the same as in the original studies. Additional analyses ${ }^{5}$. of. these.. incidents. were made in whtch the prompt feedbacks due to fuel expansion. and coolant-density.changes. were.taken. Into account. These analyses assumed the reactor.to be under full-flow concitions in all cases. The results of these analyses are sumnarlzed in Ref. 3 and are shown in Table I.under .the heading of .Subsequent Analyses. . These. results agree with those. reported in the earlier documents. The maximum reactivity inserted into the core. for the Case-5. incident: would be 1.08 (1.e., the reactor would be prompt critical), but because of the feedback effects mentloned above, would be reduced to $0.99 \$$ at the onset of fuel melting.

\footnotetext{
*The reactor period is the time required for the flux level to increase or decrease by a factor of $e$ : EBR-II is equipped with a scram mechanism that will activate if the period becomes less than $25 \mathrm{sec}$. The period trip times in the table are the actual times that would elapse between the initiation of the incidents and the scramming of the reactor by this mechanism.
} 
Effect on Fuel

\begin{tabular}{|c|c|}
\hline Case No. & ANL-5719 \\
\hline 1 & $\begin{array}{l}\text { Fuel melting after } \\
120 \text { sec }\end{array}$ \\
\hline 2 & $\begin{array}{l}\text { Fuel melting after } \\
55 \mathrm{sec}\end{array}$ \\
\hline 3 & $\begin{array}{l}\text { Probably no fuel } \\
\text { melting }\end{array}$ \\
\hline 4 & $\begin{array}{l}\text { Fuel melting before } \\
\text { insertion is com- } \\
\text { pleted }\end{array}$ \\
\hline 5 & $\begin{array}{l}\text { Fuel melting within } \\
0.17 \mathrm{sec}\end{array}$ \\
\hline
\end{tabular}

6 Fuel melting after $5.3 \mathrm{sec}$

ANL-5719A

Fuel melting after $120 \mathrm{sec}$

Fuel melting after $55 \mathrm{sec}$

Possible fuel melting after $230 \mathrm{sec}$, but eutectic temperature will be exceeded

Eutectic formation beginning after 20-50 sec

Fuel melting after $\leq 0.13 \mathrm{sec}$

Fuel melting after v6 sec
Subsequent Analyses

Fuel melting after

$121 \mathrm{sec}$

Fuel melting after $49.8 \mathrm{sec}$

Fuel melting after $220 \mathrm{sec}$; eutectic formation after v180 sec

Fuel melting after $94.5 \mathrm{sec}$

Fuel melting within $20.1 \mathrm{sec}$

Fuel melting after $5.5 \mathrm{sec}$; eutectic formation after $\sim 5.4 \mathrm{sec}$

\section{Time to Reach Trip Setpoints}

Period trip at $225 \mathrm{sec}$; powerlevel trip at $290 \mathrm{sec}$

Period trip at $\sim 9$ sec; powerlevel trip at $\sim 40 \mathrm{sec}$

Period trip at $232 \mathrm{sec}$; powerlevel trip at $2130 \mathrm{sec}$

No period trip; power--level trip at $\sim 10 \mathrm{sec}$

Period and power-level trips immediately activate; response delays may be too long to prevert melting

Period trip at 5.1 sec; powerlevel trip at $24 \mathrm{sec}$ 
Other subsequent analyses have been made for the all-metal-fueled reactor under reduced-flow conditions and for more-recent irradiation cores under reduced... and full-flow conditions. (For all the analyses, the reduced flow was $5.5 \%$ of nominal full. flow. This flow approximates that due to the auxiliary puip plus thermal convection.) Table II summarizes the results.

As under full-flow conditions, Case 5. again. represents the worst case for the all-metal-fueled reactor and would lead to fuel melting after about $0.1 \mathrm{sec}$. In each of the other cases, however, formation of the uranium alloy-stainless steel eutectic would be inftiated at the times shown in Table II, and, in most cases, coolant boiling and fuel melting would follow. As a general statement, under.reduced-flow conditions.the logs of fuelelement integrity in all but the most severe case would be due to cladding fallure rather than.centerline fuel .melting.

The reactor perlod is dependent on various. feedback effects including those of the fuel and the coolant. Because. the above.analyses were made under reduced-flow conditions, the feedback from the coolant was different than it would be under full-flow conditions. . A more detalled study of the feedback effects, which will.include an evaluation of the time required to reach the 25-sec period trip setpoint under reduced-flow conditions, will be made in the future. Comparison of Tables.I.and.II shows that the times required to reach the power-level,trip point are approximately the same under reduced-flow and full-flow conditions. . It should be noted, however, that these times are only approximate values taken.from curves intended to show overall trends rather, than absolute values.

Cases 1, 2, and 4.were analyzed for-more-recent irradiation core loadings under full-flow conditions. . Eash of these loadings contained. several subassemblies with mixed-oxide-fuel:elements and some subassemblies of experimental structural material. . It was found that fuel melting would be initiated in the oxide-fuel elements at the times shown in Table. II, but that the temperature in the metal-fuel elements would rise so slowly that: neither fuel melting nor eutectic formation would occur. . The overall.conclusion of the study of these cores at full-flow conditions is that, for the reactivity-insertion incidents considered, the initiation of fuel melting would be in the oxide-fuej. elements rather than in the metal-fuel elements. 
TABLE II. Consequences of Nuclear Incidents at Reduced Flow and for Other Types of Cores

\begin{abstract}
A11-metal-fueled Core:
Reduced Flow (5.5\% of Full F'low)
\end{abstract}

Eutectic formation after $115 \mathrm{sec}$

$\sim 100$

Eutectic formation after $45 \mathrm{sec}$

Eutectic formation after $165 \mathrm{sec}$

$\sim 130$

Fuel melting after 0.1 sec;

eutectic formation after $0.15 \mathrm{sec}$

Eutectic formation after $5.2 \mathrm{sec}$

24

\title{
Irradiation Cores: Full Flow
}

1

Oxide melting after $190 \mathrm{sec}$

metal fuel doesn't exceed $1000^{\circ} \mathrm{F}$

Oxide melting after $62 \mathrm{sec}$;

metal-fuel temperature rises

siowly

Oxide melting after 65 sec;

1ittle change in peak metal-fuel

temperature

Irradiation Cores:

Reduced Flow (5.5\% of Full Flow)

Eutectic formation at $115 \mathrm{sec}$; peak oxide temperature is $1740^{\circ} \mathrm{F}$ at this time

Eutectic formation at $46 \mathrm{sec}$; peak oxide temperature is $1680^{\circ} \mathrm{F}$ at this time 
The times required to reach the power-level trip seipoint. for Cases 1 and 2 with the recent irradiation core loadings are shown in Table II. As before, these are only approximate values, but they do show that the time required to reach the trip point at full flow. is longer for the irradiation cores than for the original all-metal-fueled core.

Analysis of Cases 1 and 2. for irradiation cores at reduced flow. showed that the order of events under these conditions is greatly different than under full-flow conditions... As shown in Table II, each of these two cases would result in the initiation of formation of the uranium alloystainless steel eutectic.in.the hottest metal fuel element before melting would be initiated in the hottest oxide-fuel element. . These events.would occur in the opposite order. In which they occur under full-flow conditions, because the coolant temperature would increase much.more rapidly during the transient. This temperature rise.would.result in a strong, negative reactivity feedback that would. limit the magnitude of the power burst. The oxide-fuel elements, because of.their.greater heat.capacity. and.significantly lower thermal conductivity, would thus be protected while the metalfuel elements could undergo eutectic formation with the stainless steel cladding.

It can be seen from. Table. II. that the times at which the power-level trip point would be reached are somewhat. shorter for irradiation cores under reduced-flow conditions than under full-flow. conditions. The trip times under reduced-flow conditions are, in fact, about the same as those for the all-metal-fuel core. This: fact. and: the above finding that. the effects of the transients. of.Cases.1.and. 2 are:greatest. on. the metal-fuel elements show that, under the Initial conditions of:zero power and reduced flow, the dynamic behavior of the reactor. is.more. dependent. upon the. behavior of the metal-fuel pins than on that of the oxide-fuel pins. On the other. hand, the behavior of the oxide-fuel pins tends to dominate under full-flow conditions.

As pointed out in.Ref。.3, measurements in.the.critical-assembly mockups in ZPR-3, the EBR-II wet critical, and during EBR-II run 37 show that the reactivity-insertion. rates used in all. the above analyses were. unrealistically high. If the more realistic rates were used, there would 
generaily be more time available. before undesirable consequences (e.g., eutectic formation and/or fuel melting) are.inltlated. There would be, therefore, a greater possibilizy of protective response and/or administrative action that could terminate the Incident and thertby avert any serious consequences.

The results presented so far have all been obtained under the assumption that the plant protective.system. (PPS). falled to respond. To. evaluate. the response of the PPS, including the delay times in the circuitry, the $s i x$. cases of reactivity insertion.have: been reanalyzed.under the assumptions of full or partial response of the. PPS.: This work has been documented. In. Ref. 4 and is summarized in. Ref. 3. The various conditions studied and. the assumptions made in Refo, 4, are: too: numerous to reiterate in the current. report. The overall conclusion made in: Ref. 4 , however, is that. there. is responsive and redundant protection for.all. the.hypothetical component malfunctions considered in. the safety. documents.

It is pointed out in Ref. 4 that-period-trip response.times of less than 50-100 msec would be required to protect the reactor In. Case. 5, the inadvertent dropning of a central subassembly.into. a just-critical reactor. The measured response times, however, are on. the order. of $300 \mathrm{msec}$, so this shutdown mechanism would not.prevent. the consequences noted earlier. It is further pointed out that a variable. power-level trip point, having. a response time of $30-50$ msec, would protect the reactor. against any serious consequences resulting from this incident.

\section{LOSS OF PRIMARY-SYSTEM FLOW}

A. Analyses in Safety Documents ANL-5719 and ANL-5719A

Another possible source of a major accident is loss of power to the primary pumps. Three major cases were: analyzed. In. the safety. documents: (I) loss of all pumping power followed. immediately by reactor scram; (II). reactor scram followed seconds later. by a loss of all pumping power; and (III) loss of all pumping power, but.with all control rods. remalning fixed in their operating.positions. In each case, the reactor was inftially at full power and full flow. 
Case I vas studied under. several. assumptions. of total control-rod worth, the degree of initial rod.insertion; and the.scram delay time. Table III shows the major consequence of. Case. I under the most-pessimistic. set of assumptions (i.e., Case.1.1. In. ANL-5719). The peak fuel temperature would be approximately $1300^{\circ} \mathrm{F}$. for this. incident and would occur about 10 sec after the loss of pumping.power... It.is.not believed that this case presents a serious.safety problem.

Case II was also studied under the: assumptions described above. Table III shows the results under the most.pessimistic assumptions. Again, there appear to be no serious. safety probleme for this incident:

As would be expected, the most. severe. 108s-of-flow. (IOF) incident. would be Case III. Under these conditions, fuel melting would begin in the hortest element within about. 3 sec...

These same LOF incidents were. reconsidered in ANL-5719A. Some modifications had been made in the plant. layout, and these: were reflected in the analysis of the incidents.: For example, mechanical. centrifugal pumps had been installed.instead of electromagnetic pumps, and, as a result, the flow coastdown is somewhat. slower than for the original system. Where applicable, the control-rod acceleration during a scram was changed to $1.5 \mathrm{~g}$ from the original value of. $3 \mathrm{~g}$. As shown in. Table III, these changes. had little effect on the original analysis. The only significant. change is that, in Case III, there is now a 30-sec delay before fuel melting would be initiated.

These incidents.were studied.later. in. a manner that took. Into. account the prompt fieedback due to fuel.expansion and coolant-density changes. As stated in Sec. VIII of Ref. 3, the results were found to be essentially the same as in the original safety documents.

\section{B. Studies of Effectiveness of Plant Protective System}

The set of LOF.studies.discussed: in Sec..A, above, has inherent assumptions regarding the response of. the. PPS... If a loss of pumping power. should actually occur while the reactor is at power, the primary flow rate would decrease and the coolant. outlet temperature, would, therefore, increase. Both of these parameters have trip points and should activate the control 
TABLE III. Fuel Temperatures upon Loss of Primary-system Flow under Most-pessimistic Assumptions: All-metal-fueled Core

Case No.

I

II Peak fuel temperature is $\sim 1330^{\circ} \mathrm{F}$

III Fuel melting in about 3 sec

ANL-5719

Peak fuel temperature is $\sim 1300^{\circ} \mathrm{F}$
-5719A

Peak fuel temperature is $\sim 1280^{\circ} \mathrm{F}$

Feak fuel temperature is $\sim 1280^{\circ} \mathrm{F}$

Fuel melting in about $30 \mathrm{sec}$
Subsequent Analyses

Essentially the same

Peak fuel temperature is $\sim 1300^{\circ} \mathrm{F}$

Essentially the same 
rods. Studies of the effectiveness, of. these trips were included in the previously mentioned analysis of the PPS. 4

The first study of the effectiveness of the coolant outlet-temperature trip was made by setting the trip pofnt at $940^{\circ} \mathrm{F}$ * Vartous time delays between the loss of pumping power.and.trip.were.assumed. It was found that the uranium alloy-stainless steel eutectic would be formed if the cielay is greater than 15-20 sec. Measured response times on the ordex of 1-2 sec have been observed.

The effectiveness of the. loweflow trip was examined by setting the trip point at $94 \%$ of full flow and varying the delay time. It was found that delay times of up to.about. 6 sec could.be allowed without leading to eutectic formation. The measured response. time of. the low-flow trips: has. been found to be approximately. $3-3 / 4$ sec, which would be sufficient to prevent eutectic formation. A. further mode of protection would be supplied by the rate-of-flow trip, which would.signal a trip when the flow is.changing at a rate of $3 \% / \mathrm{sec}$ or more. This mechanism has a measured response time of about $2-1 / 2 \mathrm{sec}$ and.would activate when the flow is approximately $97 \%$ of full flow.

It was concluded from.these studies. that there are sufficient and redundant protective levels to prevent reactor paraneters from exceeding the protective restraints on the temperatures of coolant, cladding, and fuel.

\section{Analyses of Irradiation Loadings}

Analyses of various. LOF... Incldents in cores more typical of recent Irradiation loadings have also. been made. .. These analyses accounted. for the feedback effects in the same manner as the previously mentioned studies.. The results are reported in Se... VIII of Ref...3. A wide variety of incldents were considered. Among them were: . normal coastdown after loss of pumping power; instantaneous flow.stoppage; auxiliary pump on; auxillary pump. off; one pump on and the other. off; with..trip protection; without trip protection. In each case, the. reactor was assumed to.be..under full-power and full-flow

\footnotetext{
The nominal trip point is $896^{\circ} \mathrm{F}$. The time to reach that temperature would be significantly less than the times assumed for this study.
} 
conditions at the beginning of. the incident. . A detailed analysis of each. incident is presented in Ref. 3 and.need.not.be relterated in this report. However, one major conclusion. of this study must be emphasized.: The behavior of the oxide-fueled.experimental subassembiliea was found to be greatly different than that of the metal-fueled drivers. In each case, the peak centerline temperature. of the oxide-fuel elements began an imediate. decrease due to the inherent properties of cxide fuel. The initial ber. havior of the peak temperature.in the metal-fueled.drivers, however, was. more dependent upon the assumed flow. and.trip point. conditions. The amount of auxiliary flow and the time.delay, between cessation of pumping power and reactor trip were especially. important.parameters in determining the behavior of the metal-fuel elements.

\section{FAILURE OF FUEL-ELEMENT CLADDING}

\section{A. Analyses of Effects of Flow Blockage in ANL-5719A}

The next major category of safety.considerations is that of failure of fuel-element cladding. Studies of flow blockage were originally made in $\operatorname{Re} \frac{f}{2} .2$ under the following assumptions:

1. Reactor is at. steady-state; full-power operation.

2. Maximum centerline and surface temperatures of the fuel before flow blockage are $1197^{\circ} \mathrm{F}$. and $1060^{\circ} \mathrm{F}$, respectively...

3. The blockage. material has the thermal conductivity of Type 304 stainless steel.

4. Except for Case D, below, the blockage extends the entire axiai length of the fuel element..

Five cases of flow blockage were considered, all based on the above assumptions :

A. Blockage of one. coolantrchannel. triflute.

B. Blockage around. one element to a thickness equal to the diameter of the wire wrap.

C. Blockage around part of one. element. to. a. thickress equal to the diameter of the wire wrap, but. expanding to fill an entire triflute channel for another part of the same element. 
D. Blockage in the fuel-element, grid, resulting in restriction of flow to the core section of the subassembly.

E. Same as Case A except that there are a number of blocked channels in the subassembly; no. one. fuel element, however, is in contact with more than one blocked. channel..

The results of this study are shown in Table IV and are discussed below.

For Case $\mathrm{A}$, the maximum fuel.temperature.would increase to $1213^{\circ} \mathrm{F}$ while the maximum fuel-surface. temperature would, rise to $1165^{\circ} \mathrm{F}$. Neither of the temperatures presents any safety problems.

For Case B, angles of coverage of up to. $150^{\circ}$ yielded no temperatures of serious consequence. The maximum temperatures would be about the same as those for Case $A$.

Case $C$ also would result.. in about the same maximum temperatures. Maximum fuel-centerline temperature would be $1261^{\circ} \mathrm{F}$; maximum fuel-surface temperature would be $1173^{\circ} \mathrm{F}$.

It was shown in. Case D. that: with. $50 \%$ of. the flow. area blocked ( $1 . e .$, with about $35 \%$ of nominal flow. rate), the fuel temperatures would increase less than $50^{\circ} \mathrm{F}$. However, if. the blockage should. Increase beyond this point, the uranium alloy-stainless steel. eutectic may be formed.

The analysis of Case. E. showed that the fuel. temperatures would increase very slowly as the number of blocked illow channels increased beyond one. Neither fuel melting nor eutectic formetion would result from this incident.

In summary, this series of flow-blockage studies showed that no unduly high temperatures would be reached. in the metal-fuel elements. as Ic.sg as each blockage was independent. and. no. one element was in contact with more than one blocked channe?.

\section{B. Later Analyses Related to Failures of Fuel-element Cladding}

A great deal of additional. work has been done to determine the effect of flow blockage on failure of fuel-element cladding in EBR-II subassemblfes. 
TABLE IV. Erfect of Flow Blockage on Fuel Temperatures, as Analyzed in ANL-5719A

Case No.

A

B

C

D

$\mathbf{E}$
Effect

Peak fuel temperature is $1213^{\circ} \mathrm{F}$; peak fuel-surface temperature is $1165^{\circ} \mathrm{F}$

Temperatures about same as those for Case $A$

Peak fuel temperature is $1261^{\circ} \mathrm{F}$; maximum fuel-surface temperature is $1173^{\circ} \mathrm{F}$

Fuel temperatures rise less than $50 \%$ with $50 \%$ of the flow area plugged

Fuel temperatures only slightly higher than those for Case A 
Thts work has been reported in the monthly Reactor Development Program Plogress Reports and, in some cases, in.various sections of Ref. 3 . Most of the analyses reported below are concerned with oxide-fueled subassembifes, but flow blockages in driver. and blanket. subassemblies are also discussed, because they represent revisions or extensions of the criginal flowblockage studies.

The behavior of Mark-IA, uranium-5 wt \%. fissium fuel elements subjected to flow bicckages of various degrees and to one of two nuclear. excursions has been studied. ${ }^{6}$ These excursions, described in Revision 3 of the Irradiations Guide, ${ }^{7}$.are: : (1) insextion of one control rod into a delayed critical reactor at zero power; (2) insertion of one control rod into a reactor operating at full power.. The.blockage.material was assumed to be fuel that had. collected, around. the fuel element to a thickness equal. to the diameter of the spacer.wire $\left(1_{\circ} e_{\circ}\right.$, the same as Case $B$ in the original studies, but with fuel as the blockage materlal). The angle of flow blockage was varied from 10 to $180^{\circ}$.

It was found that, for all angles of blockage considered, neither Excursion (1) nor Excursion (2) would cause the cladding temperature to reach the melting point. The highest cladding temperature for Excursion (1) was $1934^{\circ} \mathrm{F}$, which would be reached $225 \mathrm{sec}$ after the excursion began. The maximum cladding temperature. for. Excursion (2) was only $1336^{\circ} \mathrm{F}$.

Flow-blockage Cases. A, B, and D have been studied under. the assumption that oxide fuel is in the flow channels. 8 Power and flow conditions typical of those experienced by EBR-II experimental oxide-fueled subassamblies were assurined. For Case $A$, the peak cladding temperature would increase to $\sim 2170^{\circ} \mathrm{F}$, and some fuel melting would occur. For Case B, the melting point ( $2600^{\circ} \mathrm{F}$ ) of the Type 304 stainless. steel cladding. would be exceeded if the angle of flow blockage is greater than $100^{\circ}$.. Case D. was studied to determine the minimum coolant flow required for preventing coolant boiling It was found. that the flow rate could be reduced. to $\$ 30 \%$ of its nominal value before coolant bolling would be initiated.

Cases $A$ and $B$ resulted in cladding. temperatures that, although they may or may not be above the melting point of the cladding, are nonetheless much higher than the nominal values.. At these elevated temperatures, the tensile strength of the cladding is significantly less than at normal 
operating temperatures. For example, the. short-term tensile strength of unirradiated Type 304 stainless steel cladding at $2170^{\circ} \mathrm{F}$ is about $2000 \mathrm{ps} 1$. With this strength, a typical oxide-fuel element could contain an internal pressure of $~ 2300 \mathrm{psi}$. If the element is at a sufficient burnup, the internal pressure due to fission-product gases could easily be 300 psi or more, and the cladding could burst under these conditions. The short-term tensile strength of the cladding under. the conditions reached in Case $D$ is 26000 psi。 An internal pressure of 2900 . psi. could, therefore, be contained in these elements. Reference. 8 points out that the cladding of oxide-fuel elements could fall because of buildup of. Internal pressure at temperatures.below the melting point of the cladding.. An accurate analysis of this phenomenon. should, however, account for the increase in yield strength due to irradiation of the cladding. This factor. would allow greater pressures. within the fuel element (i.e., the element: could. be.taken to a higher burnup) before failure would.be anticipeted.

Analyses were done for a.flow. blockage. in. a blanket subassembly in row 7,8 , or 9.9 Both depleted uranium. and stainless steel were considered. as blocking materials. This study showed that very large angles of blockage (on the order of $240^{\circ}$ or more) would be required. to increase the cladding. temperature above the uranium-stainless steel eutectic point.

Work has also been done: ${ }^{10}$ on analyzing flow. blockage resulting from a fission-gas release. It was found that under conditions typical for an oxide-fueled experimental subassembly, a blockage over an angle of $100^{\circ}$ wculd be required before the melting point. of the cladding would be reached. Calculations of the rate of cladding-temperature increase showed that the cladding temperature would rise.to $2000^{\circ} \mathrm{F}$ in. less than 2 sec and to an equilibrium temperature of $22500^{\circ} \mathrm{F}$ in less than $20 . \mathrm{sec}$. A. high-burnup fuel element could be. Insulated. with. fission. gas for 20 sec. Therefore, If the gas insulates $a 100^{\circ}$ angle of.the cladding surface, the cladding could fall. As noted before, the decrease. In cladding strength at the eleyated temperatures, rather than the melting temperature, could be the cause of ultimate cladding failure.

Calculations were made ${ }^{11,12}$. that consideræd the case of a control rod being Inserted into a. reactor at. full power, full. Flow, and containing an oxide-fuel element blanketed by fission gas. It was found that cladding 
melting would not occur for angles of blanketing up to $80^{\circ}$. With an angle of $100^{\circ}$, however, cladding melting would be inftiated after $\sim 12 \mathrm{sec}$ for a 0.290-in.-OD element and after. $\sim 30 \mathrm{sec}$ for a 0,250-in, OD element. Sone fuel melting would take place in each case.

An experimental program 13 is. currently under way in which a number of oxide-fueled subassemblies will be irradiated until a cladding failure occurs in each. These.tests.will yleld information on the merhod. and consequences of fallure of the cladding of an unencapsulated fuel element. The possibility of failure propagation to another fuel element is of principal interest in these tests.

A task force studying the deformation of a subassembly hexagonal can as a result of fission-gas release from an oxide-fuel element has recommended. a 1000-psi limit on the pienum pressure of unencapsulated oxide-fuel elements in a subassembly without pressure-pulse protection when the subassembly is not adjacent to a safety or control. rod. and a limit of 450 psi when it is adjacent to a safety or.control. rod. Those. Iimitations should remain in effect until experimental and/or analytical evidence is available to warrant an increase in these pressures.

\section{OPERATION OF EBR-II NITH SIGNIFICANT OXIDE-FUEL CONTENT}

Most of the oxide-fuel. analyses reported in this document so far have been concerned with the safety considerations of a single oxide-fueled subassembly. Many studies have also been made.dealing with the overall behavior of reactor loadings.containing significant amounts of oxide fuel. Much of this work is discussed in. Sec. VIII of Ref。 3.

Studies of mixed cores ${ }^{14}$ ( $i_{0} e_{\text {, }}$, cores containing both metal- and oxide-fueled subassemblies). showed. that if. the reactor, when at full flow and zero power, is subjected to an uncontrolled reactivity insertion of less than $20.10 \$ / \mathrm{sec}$, oxide fuel would begin to melt before the metal fuel For insertion rates higher than $0.10 \$ / \mathrm{sec}$, however, the metal fuel would begin to melt first. This behavior is primarily due to. the greatly different thermal conductivities of.the. two types of fuels. As noted in Sec. II of this report, metal fuel would. begin. to melt first for all reactivityinsertion rates under reduced-flow conditions. 
The effects of a control-rod insertion into a core containing a 50/50 mixture of oxide and metal fuel were also. reported in Ref. 14. A parametric study of the feedback due to.fuel. expansion.and coolant-density changes was made under the assumption. that. the. reactor was at full-power and fullflow conditions at the beginning of the insertion. It was determined that. fuel would begin to melt: in the average oxide-fuel element after about 55 sec if coolant-density. changes are. the only source. of .. reactivity feedback. If the feedback from both sources. Is considered, . the. time. to the start of fuel melting is increased. to about 70 . sec. . Either of these two time intervals should be sufficiently. long. for. PPS action or administrative control to terminate the incident.

A parametric study using different values for the Doppler reactivity coefficient was also made. for. this core. and reported in Ref 14 . This study clearly showed the importance of. this parameter In allowing additional time before the initiation of. fuel melting following. a reactivity. insertion. A similar study assuming the. initial, conditions of zero power and full flow yielded the same conclusion........

In the parametric studies cised in the preceding docunent, the Dopplet coefficient reached a value of -0.001 , and. In. some of the studies cited below, it reached the same or a higher value. The values in typical EBR-II irradiation core. loadings, however, are. only. on the order of -0.0002 . Reference 15 showed. that. the Doppler. coefficient in EBR-II. could be. enhanced by the addition of sufficient. amounts of beryllium oxide. For example, a Dopfler coefficient of -0.00164 . could. be achieved. In an oxide core that contained 16.69 vol.\% of $\mathrm{BeO}_{0}$. However, the. neutron spectrum. In such a core would be considerably. softer. than. that. in the same. core without the. BeO, Friz example, the median flux energy. for the core without the BeO would be $395 \mathrm{keV}$ whereas. that. for the core with. the BeO would be only. 155 $\mathrm{keV}$. Such a softening. of. the spectrum. may be undesirable for the IMFBR experimental-irradiation program.

The high-speed Insertion of the central subassembly into a justcritical core with a. 50/50 mixture of oxide and metal fuel and at reduced flow ( $3.3 \%$ of full flow) was also analyzed in Ref. 14. These conditions 
are similar to those of Case 6 . In the safety documenis except that the core. is under reduced-flow conditions (see Table II for these results)。A Doppler reactivity coefficient of -0.0005 and a. feedback equal to that from half a metal-fueled core ( $i_{0} e_{\circ}$, neglecting the feedback from the oxide-. fuel elements) were assumed. It was found that the reactivity would reach a peak value of $96 \mathrm{c}$ before the prompt feedbacks would cause it to decrease. The peak metal-fuel temperature. would be. $1800^{\circ} \mathrm{F}$, and the peak temperature of the metal-fuel cladding would be $1758^{\circ} \mathrm{F}$. after about $10 \mathrm{sec}$. The effects of the initial reduced-flow conditions are again seen (i。e, the peak oxidefuel temperature would be only $2250^{\circ} \mathrm{F}$, well below the melting point of the fuel). The behavior of the power level and the metal fuel in this core loading is very similar to that. in the original, all-metal core. The study showed that the power: peaked at. $5.0 \mathrm{sec}$ and that the peak reactivity was $0.0070 \Delta \mathrm{k} / \mathrm{k}$. These values compare favorably to the values of $4.5 \mathrm{sec}$ and. $0.0075 \Delta \mathrm{k} / \mathrm{k}$ obtained in the original study。 Fuel melting would be initiated at $5.3 \mathrm{sec}$ in the all-metal-fueled core as compared to about $10 \mathrm{sec}$ in the mixed core.

The effects of dropping. the central subassembly into a core with a $50 / 50$ fuel mixture under. the initial conditions of zero power and $3.3 \%$ of full flow were reported in Ref. 14。 A Doppler coefficient. of -0.002 and a fuel-expansion feedback equal. to half that of an all-metal-fueled core were assumed. It was found that. the reactor would be prompt critical for a short period of time before the reactivity excursion is reversed. It was also noted that, because of the rapid heating rate of the oxide fuel, the Doppler coefficient offered a greater degree of protection than axial expansion of metal fuel in this case.

The major conclusions from these studies are:

1. An increased loading of oxide-fueled subassemblies will not compromise the inherent safety over the operating range of EBR-II.

2. The point of initial fuel melting in a core containing both metal and oxide fuel is dependent on the reactivity-insertion rate, coclantflow rate, and inherent physical properties of the fuel.

3. In a loading. that 1s predominantly oxide fuel, the combination of a Doppler coefficient of -0.001 and the normal coolant-density changes would produce an overall dynamic behavior similar to that of a present loading of predominantly metal fuel. 
4. The difference between the transient behaviors of oxide- and metal-fuel elements is due principally to their greatly different thermal conductivities.

Extensive analysis ${ }^{16}$ has been done in which not on $1 y$ the feedback due to fuel expansion but. also that due. to the collapse of molten fuel were taken into account. The feedback due to sodium-density. changes or volding was not included. . It was shown that for unbounded reactivity ramps of about $1 \$ / s e c$, the melting and subsequent slumping of the metal fuel in a mixed core would protect the reactor from a. major energy release. Additional work on a typical irradiation-core configuration showed that for unbounded ramps of 5-20\$/sec, the consequences are less severe. than they would be in an al1-metal-fueled core. Thus, the metal fuel in a mixed core serves as a protective device agalnst. major. energy releases.

The steady-state thermal-hydraulics of several mixed core configurations have been studied. 15 Operational limits and constraints that reflect the current thinking with. regard. to fuel.melting, maximum cladding temperatures, maximum allowable coolant. velocities, etc. were imposed on the oxide-fueled subassemblies in the core. Typical uncertainty factors for oxide-fuel elements were also.used. It was found that when uncertainty factors were included, the maximum fuel temperature in a fully enriched oxide-fuel element would exceed the melting point of the fuel in several of the loadings considered. These loading patterns of fully enriched oxide-fueled subassemblies were considered infeasible until a technical basis is established for operating unencapsulated oxide-fuel elements with some centerline melting.

\section{MISCELLANEOUS ANALYSES}

An analysis has been made ${ }^{17}$ of the temperature distribution within a fuel pin fabricated by infiltrating a matrix of $\mathrm{UO}_{2}$ with $\mathrm{PuO}_{2}$ spheres of a small diameter. This study was conducted to determine if, because nearly all the negative Doppler feedback is due. to ${ }^{238} \mathrm{U}$ and nearly all. the heat generation is in the plutonium, there is a signiflcant lag between the power production and the Doppler feedback. In a mixed-oxide fuel element. when a control rod is inserted into a core operating under full-power and 
full-flow conditions. The volume-welghted average temperatures of the $\mathrm{UO}_{2}$ and the $\mathrm{PuO}_{2}$ spheres were found. to be the same; therefore, there was no slgniflcant delay in the Doppler. feedback.. It is belleved that this conclusion applies to all mixedroxide. fuel elements that may be subjected to a nuclear excursion. of. similar. magnitude.

Comparisons ${ }^{18}$ have been made. between the calculated and measured. temperatures in inistrumented subassembly. xx01.: Good agreement was obtained between both the temperature. of, the coolant and the centerline temperatures of the fuel elements, thereby. giving assurance that. the computational methods. used are applicable and.accurate. Calculations also were made ${ }^{19}$ to deter-

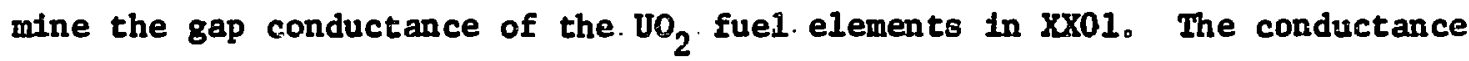
was found to be a function of. linear heat. rating and initial gap size. There was also evidence that the presance of xenon in the gap would decrease the gap conductance.

\section{CONCLUSIONS}

The overall conclusion to be drawn from the many analyses reported here is that the performance and safety of the reactor with a core having a significant oxide-fuel. Inventory. 1s not. compromised relative to that of the original all-metal-fueled core.considered in. the safety documents. In fact, there is oome. ovidence that the safety of a mixed core is somewhat improved over that of the original sore loading. 


\section{REFERENCES}

1. I. Jo Koch et al, Hazard. Sumary Report, Experimental Breeder Reactor II (EBR-II), ANL-5719 (May 1957).

2. L. J. Koch, W. B. Loewens teln, and H. O. Monson, Addendum to Hazard Summary Report, Experimental Breeder Reactor-II (EBR-II), ANL-5719 (Addendum) (June 1962)。

3. R. R. Smith, W. B. Loewenstein, and C. Mo Walter, The EBR-II: A Status Report, ANL-7743 (July 1971).

4. A. V. Campise, A Study of the Response of the EBR-II Plant. Protective. System to Hypothetical Malfunctions in the Reactor System, ANL-7665 (June 1970).

5. A. V. Camplse, A Study of the. Dynamic Response. of Various EBR-II Configurations to Hypothetical. Malfunctions in the Reactor System, ANL-7613 (November 1969).

6. Reactor Development Program Progress Report, June 1971, ANL-7833, pp. $1.8-1.10$.

7. Guide for Irradiation Experiments in EBR-II, Rev. 3, EBR-II Project document (July. 1969).

8. Reactor Development Program Progress Report, Auguet 1971, ANL-7854, PP. 1.5-1.9.

9. Reactor Development Program Progress Report, June 1970, ANL-7705, pp. 91-92.

10. Reactor Development Program Progress Report, August 1969, ANL-7606, pp. 48-49.

11. Reactor Development Program Progress Report, March 1970, ANL-7679, Pp. 72-73.

12. Reactor Development Program. Prosress Report, Apr11-May 1970, ANL7688, Pp. 112-115.

13. Reactor Development Program Progress Report, October 1970, ANL7753, pp 。 83-86:

14. A. V. Campise, The Influence of a. Predominantly Oxide Fuel Loading on the Dynamic Behavior of EBR-II, ANL-7673 (October 1970). 
15. J. L. Gillette, G。H. Golden, and.B. R. Sehgal, Neutronic and ThermalHydraulic Analyses of Mixed Cores for EBR-II, ANL-7778. (July 1971)

16. GoH。Golden and R. H。Shum, Meltdown Analysis of Var tous EBR-II Core Configurations Using the MELT-II Code, ANL-7752 (November. 1970)

17. $R_{0} K_{0}, L O$ and $N_{0} A_{0}$ McNeal, Heat Transfer in Heterogeneous UO 2 and UC-PuC Fuels in EBR-II, Trans。Am. Nuc1。Soc. 13(1), 342 (June 1970).

18. Reactor Development Program Progress Report, January 1970, ANL-7661, pp. 51-54.

19. R. A. Cushman, Gap Conductance of Oxide Fuel Elements Irradiated in EBR-II, Trans. Am. Nuc1. Soc. 13(2), 806 (November 1970). 